\title{
Breath sounds in the clinical assessment of airflow obstruction
}

\author{
ABRAHAM B. BOHADANA ${ }^{1}$, RENÉ PESLIN ${ }^{1}$, AND HUBERT UFFHOLTZ ${ }^{2}$ \\ From INSERM U 14, C.O. No. 10 ${ }^{1}$, and Service de Médecine orienté vers l'Insuffisance Respiratoire ${ }^{2}$, \\ C.H.U. Brabois, Pavillon P.L. Drouet, 54500 Vandoeuvre-les-Nancy, France
}

Bohadana, A. B., Peslin, R., and Uffholtz, H. (1978). Thorax, 33, 345-351. Breath sounds in the clinical assessment of airflow obstruction. In a group of 34 inpatients showing varying degrees of airflow obstruction we studied the relationship between breath sound intensity (BSI) and abnormalities of lung function. The BSI was evaluated by chest auscultation to provide a score, in a manner similar to that described by Pardee et al. (1976), and was found to correlate closely with indices of airflow obstruction or their logarithms such as specific conductance $(r=0.759)$, maximal expiratory flow at $50 \%$ of vital capacity $(r=0.790)$, forced expiratory volume in one second $(r=0 \cdot 768)$, and forced expiratory volume to vital capacity ratio $(r=0 \cdot 860)$. Correlations with lung volumes, although statistically significant, were weaker. Multiple correlation studies showed that BSI score correlated independently with indices of both airflow obstruction and lung distension.

In our experience, BSI score can be useful not only in the detection but also the quantification of airflow obstruction, although its predictive power is impaired in subjects with associated restrictive disorders. It can also fail to detect mild, pure airflow obstruction.

It is a current concept that the severity of functional impairment in patients with airflow obstruction is poorly related to physical signs and symptoms. Indeed, although patients with moderately severe airflow obstruction usually exhibit several symptoms and signs, assessment of obstruction on a clinical basis can be misleading and subjects with severe functional impairment may be entirely overlooked, whereas normal subjects may be misdiagnosed (Schneider and Anderson, 1965). Other studies have emphasised the relative unreliability of symptoms and signs in the evaluation of airflow obstruction, acute or chronic. Thus McFadden et al. (1973) found that dyspnoea and wheezing were inaccurate in detecting severe functional impairment in subjects with acute asthma. More importantly, evidence of considerable functional derangement during recovery was present in asymptomatic subjects. Godfrey et al. (1970) examined the correlation between several symptoms and signs and functional measurements in patients with stable, chronic airflow obstruction, and found that forced expiratory time (which can be looked on more as a physiological test) was the only sign that directly reflected the obstruction; all the others were probably related to factors such as secondary effects of the obstruction, age, or the duration of the illness.

Pardee et al. (1976) suggested recently, however, that breath sound intensity (BSI) heard at the chest could be useful in the clinical evaluation of airflow obstruction. It seems evident from their data that a clearly reduced BSI is invariably associated with an abnormal forced expiratory volume in one second $\left(\mathrm{FEV}_{1}\right)$. They also suggested that, when combined with other symptoms and signs, BSI may be an even better predictor of ventilatory function.

Considering its simplicity and potential usefulness, we decided to investigate BSI further to provide information about its possible relationships with measurements of lung function other than $\mathrm{FEV}_{1}$ and to determine more precisely the limitations of its use in daily clinical practice.

We have therefore examined groups of adult inpatients and correlated BSI with pulmonary function measurements.

\section{Methods}

SUBJECTS

Thirty-four adult inpatients were examined by one 
of us (ABB). They were unknown to the observer, and practically all were referred to our department by their private physician because of respiratory complaints. They were examined immediately after arrival and no clinical criteria of selection were adopted, except for those who had undergone pneumonectomy. This would, theoretically, enable us to see patients with different degrees of obstruction with or without associated restrictive disorders. Nevertheless, patients incapable of performing the respiratory manoeuvres correctly, thereby preventing a good BSI evaluation, were rejected from the study. During the experiments only two subjects did not meet this requirement.

The mean age (years $\pm S D)$, height $(\mathrm{cm} \pm \mathrm{SD})$, and weight $(\mathrm{kg} \pm \mathrm{SD})$ were $52 \cdot 1( \pm 13 \cdot 4), 166.4$ $( \pm 5 \cdot 1)$, and $69 \cdot 1( \pm 14 \cdot 5)$ respectively. There were 24 men and 10 women of whom 11 were smokers (10 men and 1 woman), 13 were ex-smokers (11 men and 2 women) and 10 non-smokers ( 3 men and 7 women).

\section{BSI EVALUATION}

BSI evaluation was carried out on seated patients in a fashion similar to that described by Pardee et al. (1976). Sound intensity was noted on a graderating scale, which was essentially the same as theirs, as follows: 0-absent breath sound, 1barely audible breath sound, 2-faint but definitely audible breath sound, 3-normal breath sound, and 4-louder than normal breath sound.

Auscultation was performed in the following chest zones, bilaterally-upper anterior, midaxillae, and posterior base. Subjects were asked to perform fast, deep inspirations from residual volume to generate as loud a sound as possible while breathing through the mouth. Whenever necessary they were taught to breathe without making too much noise at the mouth. They were allowed to rest between the examination of two zones whenever they looked tired and showed a tendency not to mobilise their best inspiratory flows. The final BSI score was obtained by taking the sum of the values of each individual zone, and care was taken to note the latter separately, since an identical final BSI score in different subjects was not incompatible with considerable interzonal variations. Possible final BSI score ranged from 0 to 24 .

In a preliminary study BSI inter-observer variability was determined by the separate examination of 20 unknown inpatients and outpatients independently by two of us (ABB and HU) at fiveminute intervals. Both observers used the same stethoscope. A good general agreement was arrived at by both examiners despite a slight tendency for one of them (ABB) to overestimate BSI, as compared to the other (Fig. 1). There was some disagreement when, in a given subject, scores from the individual zones were compared. Discrepancies between observers were noticed in 25 zones (out of 120) and ranged from 1 point (24 cases) to 2 points ( 1 case).

Among the possible reasons underlying these differences one must be remembered because its role may be important-namely, slight differences between the examiners' levels of sound reference. Taking this into account it seems wiser to consider as abnormal a BSI $\leqslant 16$ rather than $<18$.

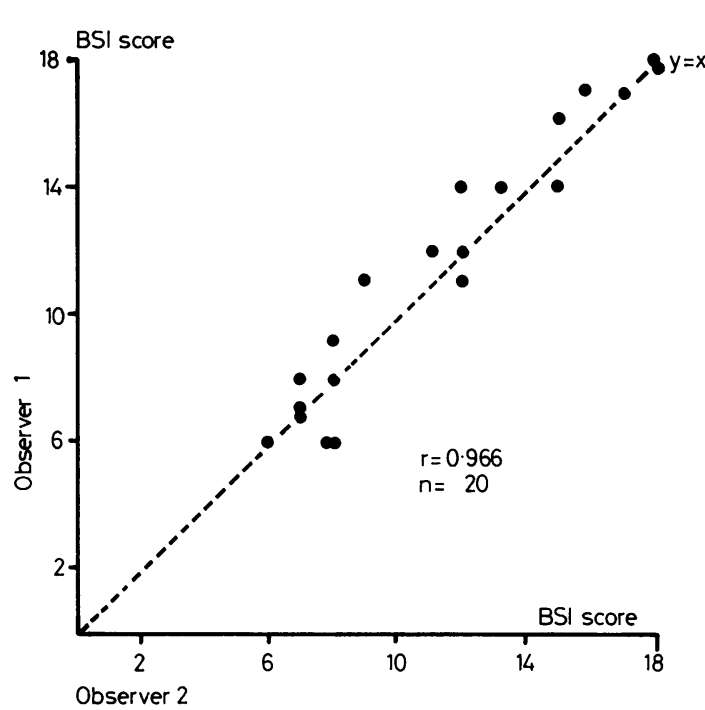

Fig. 1 Correlation between BSI score as evaluated by two observers independently (observer $1, A B B$; observer 2, HU). Slope of regression of $y$ on $x$ (not represented) is not significantly different from zero at $5 \%$ level.

PULMONARY FUNCTION TESTS

Before undergoing pulmonary function tests, $\stackrel{N}{N}$ subjects were allowed a short period of rest.

Lung volume, and its subdivisions, and airwayo resistance were measured using a constant-volumeo body-plethysmograph (Fenyves et Gut Medizinische Electronik). Airways resistance was measured? during quiet breathing, converted to its reciprocal, the conductance, and expressed as specific conductance $($ SGaw $=$ Gaw $/$ FRC). Functional residua capacity (FRC) was determined by the method of Dubois et al. (1956). Total lung capacity (TLC) was obtained by adding the inspiratory capacity Results were expressed as a percentage of the pre-O응 
dicted values of Amrein et al. (1970). Maximal expiratory flow-volume curves were obtained when the subjects performed several (four at least) forced vital capacity manoeuvres while sitting in the body-box that now communicated through a metal screen with the exterior. Pressure drop through the screen was proportional to flow, whose integrated signal allowed, after corrections for gas compressibility, recording of volume. Flow at the mouth was measured with a calibrated Fleisch no. 3 pneumotachograph and displayed against volume on an $x-y$ recorder (Bryans). Flows were measured at $50 \%$ of the vital capacity (VC) and the results expressed as a percentage of the predicted values of Knudson et al. (1976). After another short period of rest, spirometric measurements were carried out using a 9-litre watersealed spirometer (G. Boulitte). From the best of at least three slow inspiratory or expiratory vital capacity manoeuvres (Hutchinson et al., 1973) and three forced expiratory manoeuvres, the following indices were derived: slow $\mathrm{VC}, \mathrm{FEV}_{1}$, and $\mathrm{FEV}_{1} / \mathrm{VC}$.

After correction to BTPS, values were expressed as a percentage of the predicted values of the
European Coal and Steel Community (1971), except for $\mathrm{FEV}_{1} / \mathrm{VC}$ ratio, which was expressed as the observed value.

\section{Results}

No significant correlations were found between BSI score and age, weight, or height. Although they were not very close, correlations between the BSI score and the lung volumes were statistically significant (Fig. 2).

When we plotted the BSI score against several indices of obstruction or their logarithms, a strong correlation emerged whatever the index and, whereas the relationship was linear when the BSI score was plotted against $\mathrm{FEV}_{1}$ and $\mathrm{FEV}_{1} / \mathrm{VC}$, it was curvilinear when we used indices such as $V \max _{50}$ VC and SGaw (Fig. 3). This implies that whereas the BSI score begins to deteriorate at relatively high values of $\mathrm{FEV}_{1}$ and $\mathrm{FEV}_{1} / \mathrm{VC}$ ratio it does so only at lower values of $V \max _{50}$ VC and SGaw.

It was also interesting to test, by multiple linear regressions, whether BSI score was better explained by lung distension and airway obstruction

\section{BSI Score}
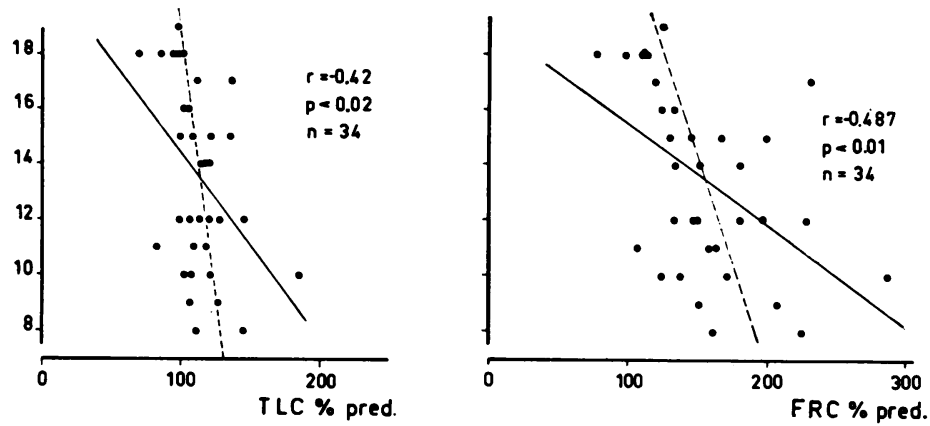

BSI Score

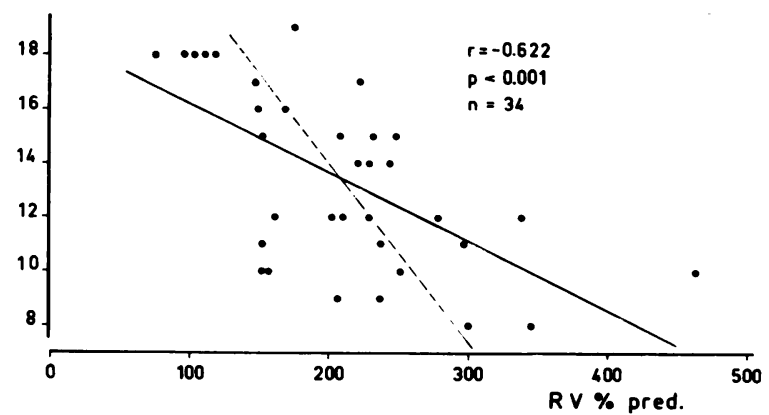

Fig. 2 Correlations between BSI score and lung volumes. Solid lines represent regression of $y$ on $x$, dashed lines represent regression of $x$ on $y$. 
BSI Score
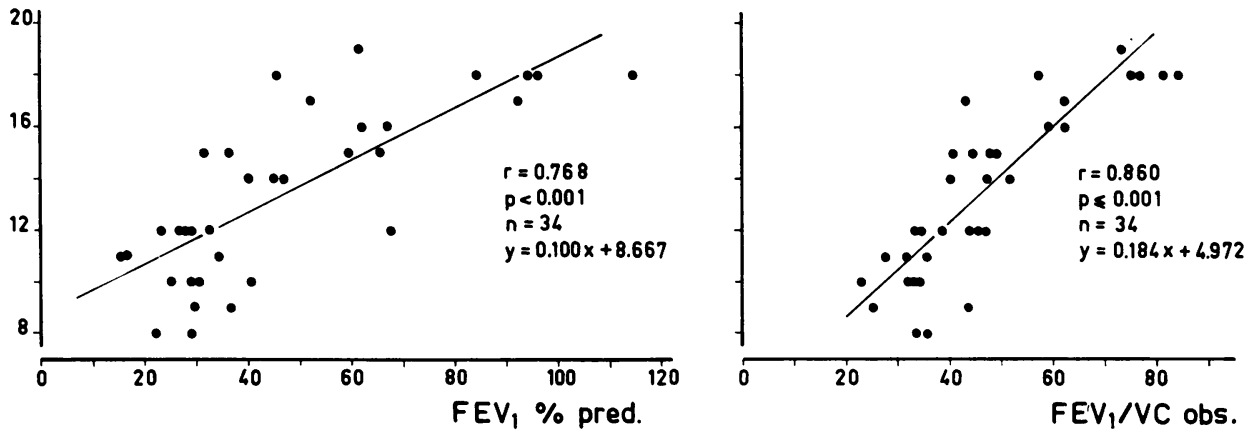

BSI Score
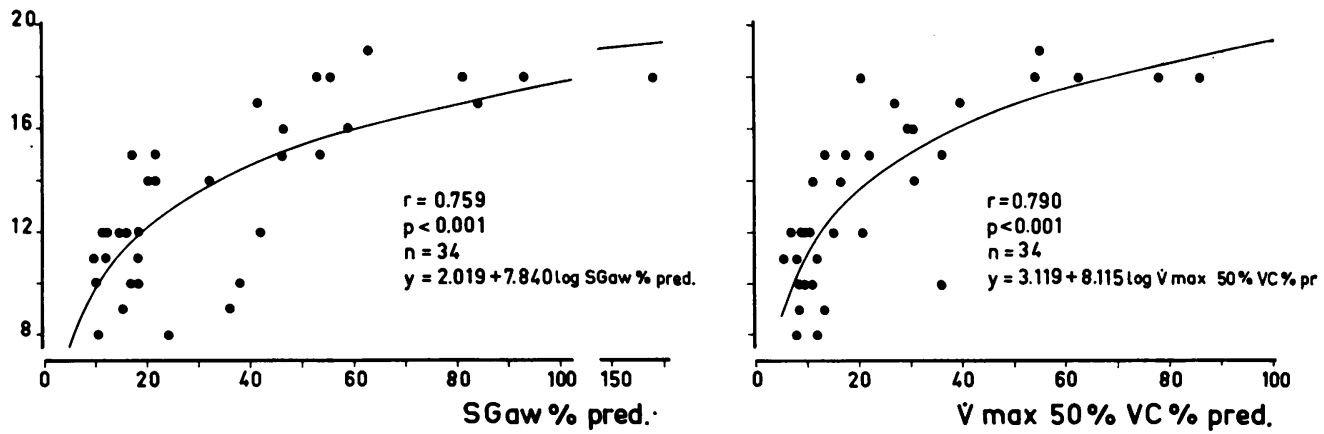

Fig. 3 Correlations between BSI score and four indices of obstruction or their logarithms.

rather than by each of these factors taken alone. For this, we selected functional indices that were not significantly correlated between themselves, that is TLC for distension and $V \max _{50} V C$ or SGaw for obstruction. As shown in Table 1 the multiple regressions are highly significant with $\mathbf{r}$ values substantially higher than those obtained from simple regression (Figs. 2 and 3 ); all slope coefficients are significantly different from zero. BSI score may, therefore, be considered as independently correlated to both distension and obstruction.

\section{Discussion}

The loudness of breath sounds heard at the chesर depends mainly on two factors, both or either of which can modify the BSI-namely, the sound intensity at the site of generation and the transe mission properties of the aerated lung and chesk wall. Although an extensive review of the mech은 anisms governing both factors is beyond the scoped of this study, some physiological considerations. are necessary for a better understanding of oun results.

Table 1 Multiple linear correlations between BSI score and indices of airflow obstruction and lung distension

\begin{tabular}{|c|c|c|c|c|c|c|c|c|c|}
\hline$x$ & $y$ & $r x, y$ & $P_{1}$ & $a$ & $b$ & $c$ & see & $r z, x y$ & $P_{2}$ \\
\hline $\begin{array}{l}\text { TLC } \\
\% \text { pred } \\
\text { TLC } \\
\% \text { pred }\end{array}$ & $\begin{array}{l}\log \text { Vmax } \\
50 \% \text { CV (\% pred) } \\
\log \text { SGaw } \\
\text { (\% pred) }\end{array}$ & $\begin{array}{l}-0.095 \\
-0.271\end{array}$ & $\begin{array}{l}P>0.1 \\
P>0.1\end{array}$ & $\begin{array}{l}9.74 \\
7.07\end{array}$ & $\begin{array}{l}-0.055 \\
-0.036\end{array}$ & $\begin{array}{l}7.77 \\
7.19\end{array}$ & $\begin{array}{l}1.73 \\
2.09\end{array}$ & $\begin{array}{l}0.862 \\
0.790\end{array}$ & $\begin{array}{l}<0.001 \\
<0.001\end{array}$ \\
\hline \multicolumn{10}{|c|}{$\begin{array}{l}x, y=\text { independent variables. } \\
r x, y=\text { correlation coefficient of the independent variables. } P_{1}=\text { corresponding statistical significance. } \\
a, b, c=\text { coefficient of the multiple regression } Z=a+b x+c y \text { where } Z \text { is the BSI score. } \\
\text { see }=\text { standard error of the estimate of the regressions. } \\
r z, x y=\text { correlation coefficients of the multiple regressions. } P_{2}=\text { corresponding statistical significance. }\end{array}$} \\
\hline
\end{tabular}




\section{SOUND GENERATION}

It is generally accepted that, in healthy subjects, breath sounds are generated in the central airways as a result of turbulent airflows (Forgacs et al., 1971; Banaszak et al., 1973). Indeed, there is good evidence that turbulence exists in many points of the tracheobronchial tree, even during quiet breathing. Thus Olson et al. (1972) using casts of human airways were able to show that turbulence is present in the trachea and proximal bronchi at flows as low as $200 \mathrm{ml} \mathrm{s}^{-1}$. On the other hand, calculations by Pedley et al. (1977) show that, for values of inspiratory flows around $21 \mathrm{~s}^{-1}$, turbulence is present in the trachea and may persist up to the fourth or fifth bronchial generation. Because sounds generated by turbulence are poorly transmitted however, their intensity is greatly decreased, and it is doubtful whether they are heard at the chest wall (Olson, 1973). Recent work by Ploy-Sang-Song et al. (1977) suggests that vesicular breath sounds are not simply transmitted sounds from central airways but are generated more peripherally (in sites between bronchioles $3 \mathrm{~mm}$ diameter and alveoli) and are related to nonturbulent, density-dependent airflow.

Regardless of the site of sound generation and of its precise production mechanisms, BSI heard at the chest is influenced by the magnitude of the inspiratory flow as well as by the number of patent airways leading to the zone of auscultation. The influence of flow on BSI score can be easily demonstrated, and we did so in a group of five healthy, well-trained subjects from the laboratory. Each subject was asked to perform a series of inspiratory manoeuvres at constant flows while breathing through a pneumotachograph. Flows were kept constant with the aid of an oscilloscope. The examiner (ABB) was not aware of the flows being generated, which were freely chosen by the subjects from five preset values ranging from $0.51 \mathrm{~s}^{-1}$ to $31 \mathrm{~s}^{-1}$. As in the patients, BSI score was also assessed during maximal inspiratory flows. As shown in Fig. 4, BSI score was found to increase linearly with the increasing flows. This agrees well with the observations of Leblanc et al. (1970), although these authors' experiments were somewhat different, as breath sound intensity and inspiratory flows were recorded graphically at given lung volumes.

Unfortunately, we were not able to evaluate the influence of flow on BSI score successfully in patients because, in general, they were not able to generate constant flows often and long enough to allow a good BSI score assessment. Also, their relatively small inspiratory flows did not allow us to study BSI in a range of flows as wide as in

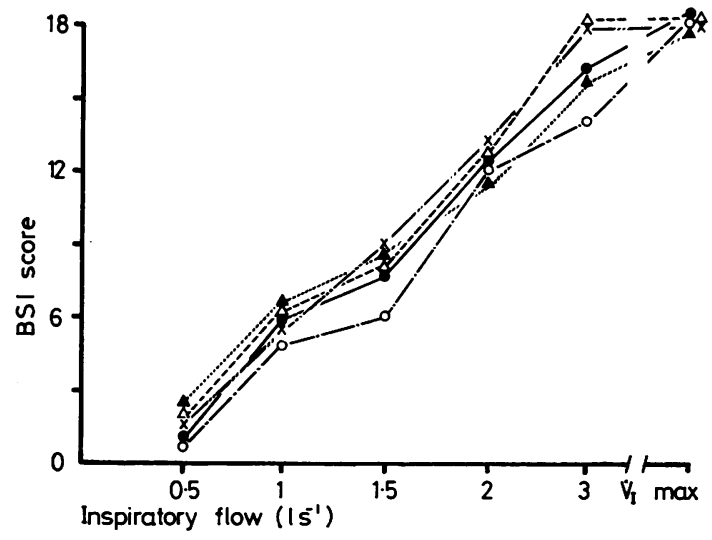

Fig. 4 BSI score at several constant inspiratory flows in five healthy subjects. At a flow of $0.5 \mathrm{l} \mathrm{s}^{-1}$ breath sounds were inaudible in basal regions in all subjects.

normal subjects. Nevertheless, there is no reason to believe that in diseased subjects BSI would not be flow-dependent. In fact we think that decreased inspiratory flows, probably associated with a diminished number of patent airways, is one of the major factors determining the decrease in the BSI score found in our subjects with airflow obstruction. Thus it is not surprising that good correlations were observed between the BSI score and various indices of obstruction, although the latter were obtained during forced expirations.

\section{SOUND TRANSMISSION}

As recently emphasised by Ploy-Sang-Song $e t$ al. (1977) sound transmission is important and is considered separately from the sound intensity at the source only for the sake of clarity; indeed they are closely related and BSI at the chest wall will depend on how they interact. Thus the sound must travel from the site of generation to the point of auscultation over the chest through the aerated lung tissue, which acts as a selective bandpass filter (Banaszak et al., 1973). In conditions such as lung distension the distance to be travelled by the sound increases, and consequently sound energy and BSI will decrease. If one considers that linear distances in the lungs change as the cube root of the volume changes, when the lung volumes increase by a factor of three (a rather exceptional finding), the distance between the site of sound generation and the point of auscultation will increase by only $45 \%$. This does not mean necessarily that BSI score will decrease in the same proportion. Indeed, calculations using the multiple linear regressions show that, in the above circumstance, the BSI score will be severely decreased 
even if flows are kept in the normal range. In clinical practice increases in lung volume by a factor of two or three are less common than decreases in flow by similar factors. Because lung distension was less pronounced than decrease in flows, its contribution to a diminished BSI score was smaller in most of our patients: to take the average figures in the group, the increase in TLC $(112.9 \%$ pred) would be responsible for a decrease in BSI score of less than one point, while the decrease in $V \max _{50}$ VC (24.6\% pred) would lead to a decrease of around four points.

It should be noted that while transmission effects add to those of decreased flows in subjects with lung distension they can counterbalance the effects of low flows in subjects with associated restrictive disorders. An illustration is given in Table 2 where two subjects with lung distension and restrictive disease (histiocytosis $\mathrm{X}$ ) and who show similar degrees of airflow obstruction are compared. Using the multiple regression equations (Table 1) the expected BSI score difference ( 2.5 points) agreed well with the observed one, suggesting that the latter is mainly due to differences in lung volumes and consequently in sound transmission properties. Although it is possible that the transmission effect is mostly a matter of longer or shorter distance between the site of sound generation and the point of auscultation, the quality of the lung parenchyma may also influence the BSI. It is well known from clinical practice and from published reports (McKusick et al., 1955) that sound-conducting properties are enhanced by consolidated lung tissue and that in such circumstances bronchial breath sounds can be heard at the chest.

Table 2 Comparison of two patients with restrictive disorder and lung distension who show similar degrees of airflow obstruction

\begin{tabular}{|c|c|c|}
\hline Indices & $\begin{array}{l}\text { Subject with } \\
\text { restrictive disorder }\end{array}$ & $\begin{array}{l}\text { Subject with } \\
\text { lung distension }\end{array}$ \\
\hline $\begin{array}{l}\text { BSI score } \\
\text { TLC (\% pred) } \\
\text { RV ( \% pred) } \\
\text { FEV } 1 \% \text { pred }) \\
\text { SGaw }(\% \text { pred) } \\
\text { Vmax } \\
\left.\text { smo }_{0} \text { VC } \% \text { pred }\right)\end{array}$ & $\begin{array}{l}18 \\
69 \\
118 \\
45.4 \\
53 \\
20.4\end{array}$ & $\begin{array}{r}15 \\
135 \\
248 \\
59.5 \\
53.4 \\
36.2\end{array}$ \\
\hline
\end{tabular}

BSI differences between two subjects with similar degree of airflow obstruction but different lung volumes can be accounted for by transmission properties (see text).

Breath sound intensity as evaluated in this study can be used as a valuable clinical means of assessing airflow obstruction. It appears to be quite specific, and notation using a grade rating scale contributes to reduce inter-observer disagreement as pointed out by Pardee et al. (1976). Neverthe less, a short period of training seems desirable is comparable data are to be collected by differen physicians. It must also be remembered that botlf physicians' and patients' motivation is most im portant if a good BSI evaluation is to be obtained and the examiner must be sure that the patient is. generating his best flows. BSI sensitivity seems to be only moderate, and it can fail to detect milॄ pure airflow obstruction as well as obstruction in subjects with associated restrictive disorders.

The BSI score should obviously not replacê functional measurements, but it can be extremel useful when a lung function laboratory is notw available or even when, despite a good laboratorys the patient cannot for some reason undergo re옥 peated functional assessment. Furthermore, it canbe very useful in medical teaching as it is relatec to several physiological and pathophysiologica aspects of the respiratory system.

\section{References}

Amrein, R., Keller, R., Joos, H., and Herzog, Hš (1970). Valeurs théoriques nouvelles de l'exploration de la fonction ventilatoire du poumon. Bulletin d Physio-Pathologie Respiratoire, 6, 317-349.

Banaszak, E. F., Kory, R. C., and Snider, G. L $\cong$ (1973). Phonopneumography. American Review os Respiratory Diseases, 107, 449-455.

Commission of the European Communities (1971)? Aide mémoire pour la pratique de l'examen de la. fonction ventilatoire par la spirographie. Collection d'hygiène et de médecine du Travail no. 11, 2nळ్ edition, Luxembourg.

DuBois, A. B., Botelho, S. Y., Bedell, G. N., Marshalle R., and Comroe, J. H. (1956). A rapid plephysmo graphic method for measuring thoracic gas volume a comparison with nitrogen washout method fos measuring functional residual capacity in normal sub jects. Journal of Clinical Investigation, 35, 322-326응

Forgacs, P., Nathoo, A. R., and Richardson, H. D (1971). Breath sounds. Thorax, 26, 288-295.

Godfrey, S., Edwards, R. T. H., Campbell, E. J. M.N and Newton Howes, A. D. (1970). Clinical an®r physiological associations of some physical signs observed in patients with chronic airways obstrucN tion. Thorax, 25, 285-287.

Hutchison, D. C. S., Barter, C. E., and Martelliर N. A. (1973). Errors in the measurement of vitap capacity. A comparison of three methods in norma subjects and in patients with pulmonary emphy? sema. Thorax, 28, 584-587.

Knudson, R. J., Slatin, R. C., Lebowitz, M. D., and Burrows, B. (1976). The maximal expiratory flow $\vec{\Phi}$ volume curve. Normal standards, variability an effects of age. American Review of Respiratory Diseases, 113, 587-600.

Leblanc, P., Macklem, P. T., and Ross, W. R. Do (1970). Breath sounds and distribution of pulmonario 
ventilation. American Review of Respiratory Diseases, 102, 10-16.

McFadden, E. R., Kiser, R., and de Groot, W. J. (1973). Acute bronchial asthma. Relation between clinical and physiologic manifestations. New England Journal of Medicine, 288, 221-225.

McKusick, V. A., Jenkins, J. T., and Webb, G. N. (1955). The acoustic basis of the chest examination: Studies by means of sound spectrography. American Review of Tuberculosis, 72, 12-34.

Olson, D. E., Iliff, L. D., and Sudlow, M. F. (1972). Some aspects of the physics of flow in the central airways. Bulletin de Physio-Pathologie Respiratoire, $8,391-408$.

Olson, D. (1973). Discussion in Forgacs, P. Noisy breathing. Chest, 63, 38s-41s.

Pardee, N. E., Martin, C. J., and Morgan, E. H. (1976). A test of the practical value of estimating breathing sound intensity. Breath sounds related to measured ventilatory function. Chest, 70, 341-344.
Pedley, I. J., Schroter, R. C., and Sudlow, M. F. (1977). Gas and mixing in the airways, in Bioengineering A spects of the Lung, edited by J. B. West, p. 163. Dekker, New York.

Ploy-Song-Sang, Y., Martin, R. R., Ross, W. R. D., Loudon, R. G., and Macklem, P. T. (1977). Breath sounds and regional ventilation. American Review of Respiratory Diseases, 116, 187-197.

Schneider, I. C., and Anderson, A. E. (1965). Correlation of clinical signs with ventilatory function in obstructive lung disease. Annals of Internal Medicine, 62, 477-485.

Requests for reprints to: Dr. A. B. Bohadana, INSERM U 14, C.O. No. 10, C.H.U. Brabois, Pavillon P.L. Drouet, 54500 Vandoeuvre-les-Nancy, France. 